\title{
HEAT TRANSFER ANALYSIS OF A HIGH-TEMPERATURE HEAT PIPE- ASSISTED LATENT HEAT THERMAL ENERGY STORAGE SYSTEM ENHANCED BY METAL FOAM
}

\author{
Saeed Tiari ${ }^{{ }^{*}}$, Mahboobe Mahdavi ${ }^{1}$ \\ ${ }^{1}$ Gannon University, Erie, PA 16541, USA
}

\begin{abstract}
Numerical simulations are performed to analyse the thermal characteristics of a latent heat thermal energy storage system with phase change material embedded in highly conductive porous media. A network of finned-heat pipes is also employed to enhance the heat transfer within the system. ANSYS-FLUENT 19.0 is used to create a transient multiphase computational model to simulate the thermal behavior of the storage unit. Copper foam is the porous media used to enhance the heat transfer and is impregnated with the phase change material, potassium nitrate $\left(\mathrm{KNO}_{3}\right)$. The effects of porosity of the metal foam and quantity of heat pipes on the thermal characteristics of storage unit during the charging process have been studied.
\end{abstract}

KEY WORDS: thermal energy storage, charging, porous media, copper foam, heat pipe, phase change material

\section{INTRODUCTION}

Latent heat thermal energy storage (LHTES) systems are one the most promising solutions to resolve the intermittency problem of concentrated solar power generation systems. They are also widely used in electronics cooling and heating and hot water systems $[1,2]$. These systems can store significantly higher amount of thermal energy in comparison to a sensible heat thermal energy storage system of the same size due to large latent heat of fusion of the phase change materials (PCM) used in them. However, most commonly used PCMs offer relatively low thermal conductivity which leads to lengthy charging and discharging processes. To resolve this issue, various passive heat transfer enhancement techniques have been implemented. Inserting fins [3], dispersion of highly conductive nanoparticles within the PCM [4,5] and embedding passive heat transfer devices such as heat pipe [6] is are common techniques to improve the thermal performance of LHTES systems.

Impregnation of highly conductive porous media such as metal foams with PCM is another method that has been used to enhance the heat transfer in LHTES systems. The effects of employing highly conductive porous media on the thermal performance of LHTES systems have been examined in several experimental and computational investigations. Majority of these studies focus on utilization of low melting temperature PCMs. Buonomo et al. [7] numerically studied the effect of utilizing aluminium foam on the thermal behaviour of Rubitherm RT58 PCM. It was found that employing the porous media leads to the increase of the overall heat transfer by a magnitude of two in comparison to the case without porous media. Shahsavar et al. [8] numerically investigated the combined effects of copper foam and surface waviness on thermal performance of Rubitherm RT35 within a vertical double-pipe LHTES unit. Their results indicated that that employing copper foam/PCM composite and wavy channel accelerates both melting and solidification processes significantly in comparison to smooth channels with pure PCM. Zhu et al. [9] studied the melting process of paraffin wax embedded in aluminium foam. The results indicated that the PPI (pores per inch) of 
the aluminium foam, the shape of cold wall and the distribution of heat sources influence the thermal behaviour of the foam/PCM composite significantly.

As mentioned previously, employing passive heat transfer devices such as heat pipes (HP) and thermosyphons is another technique to enhance the heat transfer within the PCM. Heat pipes can transport considerable amount of thermal energy over a comparably long distance with a relatively small temperature difference. The charging process of a thermal storage unit with high-temperature PCM embedded in metal foam is studied numerically in the current study. The PCM/copper foam composite is enclosed by a square container. The charging process starts by applying a constant temperature higher than the melting temperature of the phase change material to the bottom wall of the container, which was initially at room temperature. A transient two-dimensional multiphase computational model is created using ANSYSFLUENT 19.0 to study the thermal performance of the storage unit. The effects of porosity of the metal foam and quantity of heat pipes are studied on the thermal response of the system during charging process.

\section{PHYSICAL AND NUMERICAL MODEL}

The schematic of the thermal energy storage unit is shown in Fig. 1. Constant high temperature is applied to the HP evaporator section, which covers the bottom surface of the PCM container. Nickel fins are mounted on the condenser of the heat pipes to provide a better heat transfer within the phase change material. The geometrical specifications and the thermophysical properties of different components of the system can be found in another paper published by the authors earlier [6]. The entire storage unit is initially at $27^{\circ} \mathrm{C}(300$ $\mathrm{K})$ and the charging of the system starts by applying a constant temperature of $350^{\circ} \mathrm{C}(623 \mathrm{~K})$ to the $\mathrm{HP}$ evaporator section. The PCM used in this study is potassium nitrate with melting temperature of $335^{\circ} \mathrm{C}(608$ $\mathrm{K}$ ) which is embedded in copper foam. The properties of different types of copper foam used in this study are listed in Table 1.

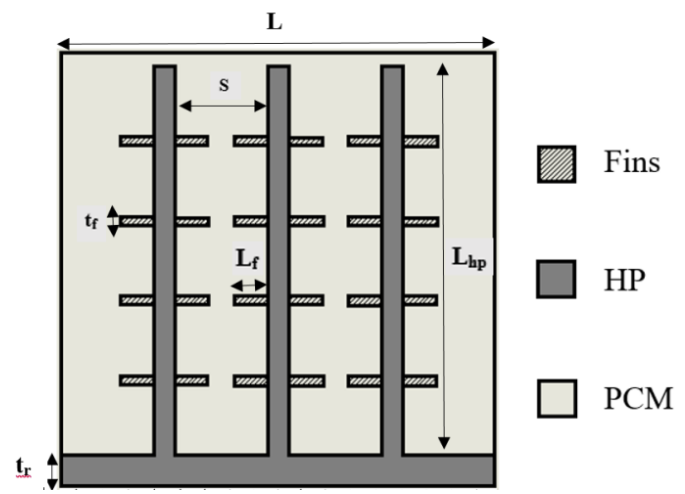

Fig. 1 Schematic of thermal storage unit with three embedded heat pipes.

To model the phase change process, enthalpy-porosity technique is used. A transient multiphase twodimensional computational model is created using ANSYS-FLUENT 19.0. Additional information about the numerical procedure, model validation, governing equations and the results mesh and time step dependence tests can be found in authors' previously published studies $[4,10]$.

Table 1 Dimensions and properties of the porous media (copper foams).

\begin{tabular}{c|ccccc}
\hline $\begin{array}{c}\text { porosity } \\
\varepsilon\end{array}$ & $\begin{array}{c}\text { Fiber Diameter } \\
d_{f}(\mathrm{~mm})\end{array}$ & $\begin{array}{c}\text { Pore Diameter } \\
d_{p}(\mathrm{~mm})\end{array}$ & $\begin{array}{c}\text { Permeability } \\
\mathrm{K} \times 10^{8}\left(\mathrm{~m}^{2}\right)\end{array}$ & $\begin{array}{c}\text { Inertial } \\
\text { Coefficient, } \mathrm{C}_{\mathrm{f}}\end{array}$ & $\begin{array}{c}\text { Effective Thermal } \\
\text { Conductivity, } \mathrm{k}_{\text {eff }}(\mathrm{W} / \mathrm{m} . \mathrm{K})\end{array}$ \\
\hline 0.9091 & 0.25 & 1.935 & 5.06 & 0.08254 & 12.47 \\
\hline 0.972 & 0.23 & 1.8 & 5.2 & 0.094 & 4.86 \\
\hline
\end{tabular}

\section{RESULTS AND DISCUSSIONS}

The effect of metal foam porosity on the PCM liquid fraction during the charging is shown in Fig. 2 for the cases assisted by one and three HPs. Here, the pure PCM, and metal foam with porosities of 0.972 and 0.9091 are 
considered. The entire phase change material is initially solid at $300 \mathrm{~K}$ when the charging process starts. At the early stages of charging, significantly faster melting rates can be seen for the cases with metal foam in comparison to the case with pure PCM. The heat transfer is dominated by conduction and influence of natural convection is almost negligible due to existence of relatively thin layers of liquid PCM. As the figure shows at this stage embedding the PCM within the metal foam enhances the heat transfer as it improves the phase change material effective thermal conductivity. As charging process proceeds and thicker layer of liquid is formed, the effects of natural convection become stronger which accelerates the melting progress. However, in the case with metal foam, the motion of the molten salt and generally natural convection is suppressed due to the presence of the porous media. Therefore, the melting progresses faster in the case with the pure PCM compared to the case with PCM/metal foam composite with porosity of 0.972 and results in the lower total charging time. As the porosity of the foam decreases to 0.9091 , the conductivity enhancement becomes more significant and outweighs the suppression of natural convection. The total charging time of the storage unit decreases considerably with the decrease of the porosity of the copper foam. In the cases assisted by one HP, it takes around 12000 seconds for the entire PCM to melt when a metal foam with porosity of 0.972 is used, which is higher than that of the case with pure potassium nitrate. It should be noted that for the case with the PCM/foam composite with porosity of 0.9091 the charging time is around 6800s. In the cases assisted by three HPs, the total charging process takes around $2860 \mathrm{~s}$ for the case with pure PCM with no metal foam, while it is about and 1610 $\mathrm{s}$ and $880 \mathrm{~s}$ for the systems with metal foam with porosities of 0.972 and 0.9091 , respectively.

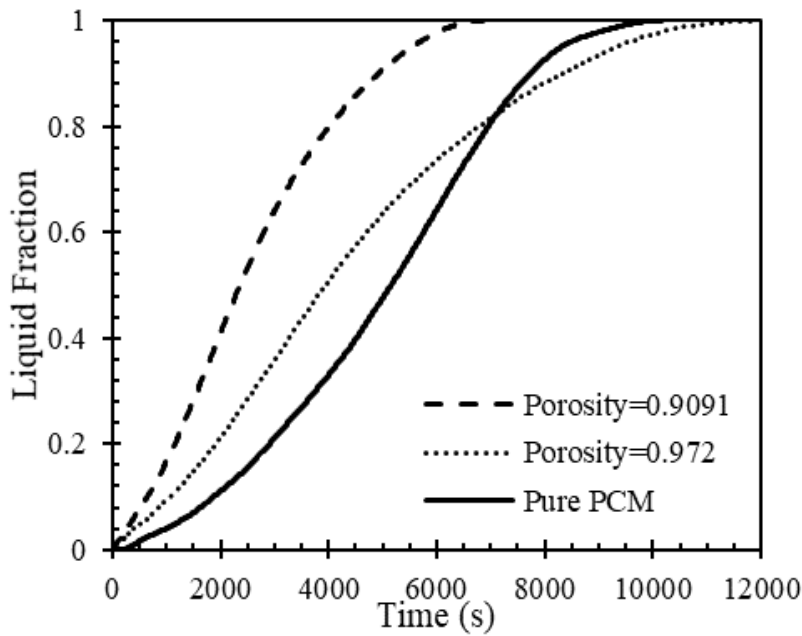

(a)

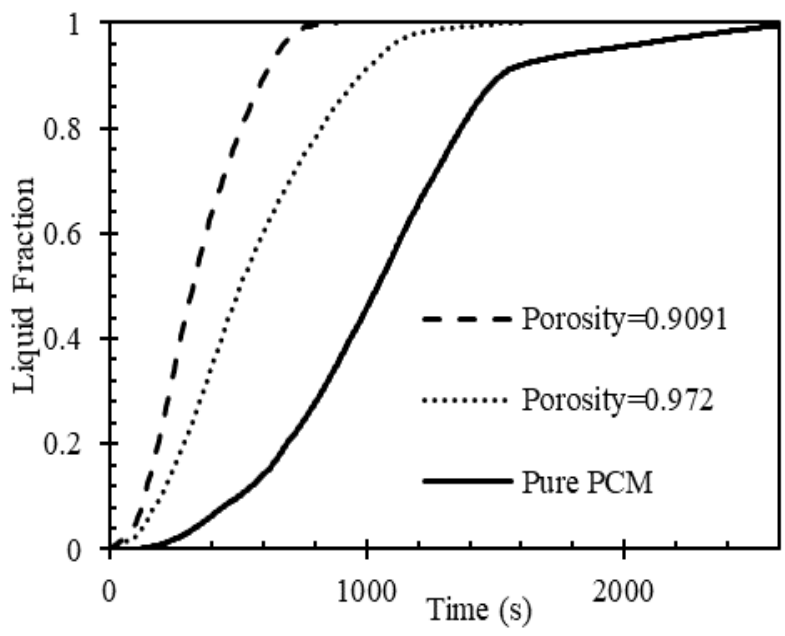

(b)

Fig. 2: Effect of copper foam porosity on liquid fraction of the cases with: (a) one and (b) three HPs

Fig. 3 shows the temperature distribution within the thermal storage unit assisted by three heat pipes and different metal foam porosities at different times. The most uniform temperature distribution within the phase change material can be observed in the case with porosity of 0.9091. Embedding the PCM within the metal foam and decreasing the porosity of the metal foam brings down the temperature difference between the heat pipes and the PCM. At $\tau=300 \mathrm{~s}$, there is a $150 \mathrm{~K}$ temperature difference between the heat pipes and the solid layers of PCM away from them in the case with pure PCM. However, at the same time the entire system shows the same uniform temperature for the case with PCM embedded within the metal foam with porosity of 0.9091.

\section{CONCLUSIONS}

The charging of a thermal energy storage unit with high-temperature PCM assisted by highly conductive porous media and finned-heat pipes was investigated numerically. ANSYS-FLUENT 19.0 was used to create the multiphase transient computational model. Potassium nitrate was used as the PCM. Copper foam was the porous material impregnated by the PCM to enhance its effective thermal conductivity. The effects of embedding the PCM within the metal foam with different porosities and inserting different numbers of heat 
pipes on the liquid fraction and temperature distribution of the PCM were investigated. Embedding the phase change material within copper foam can significantly affect the total charging time of the storage unit. Numerical analysis also indicated the porosity of the impregnated metal foam has considerable effects on the melting of the salt. For the cases studied, decreasing the porosity of the metal foam accelerates the charging process and leads to a more uniform temperature distributions within PCM.
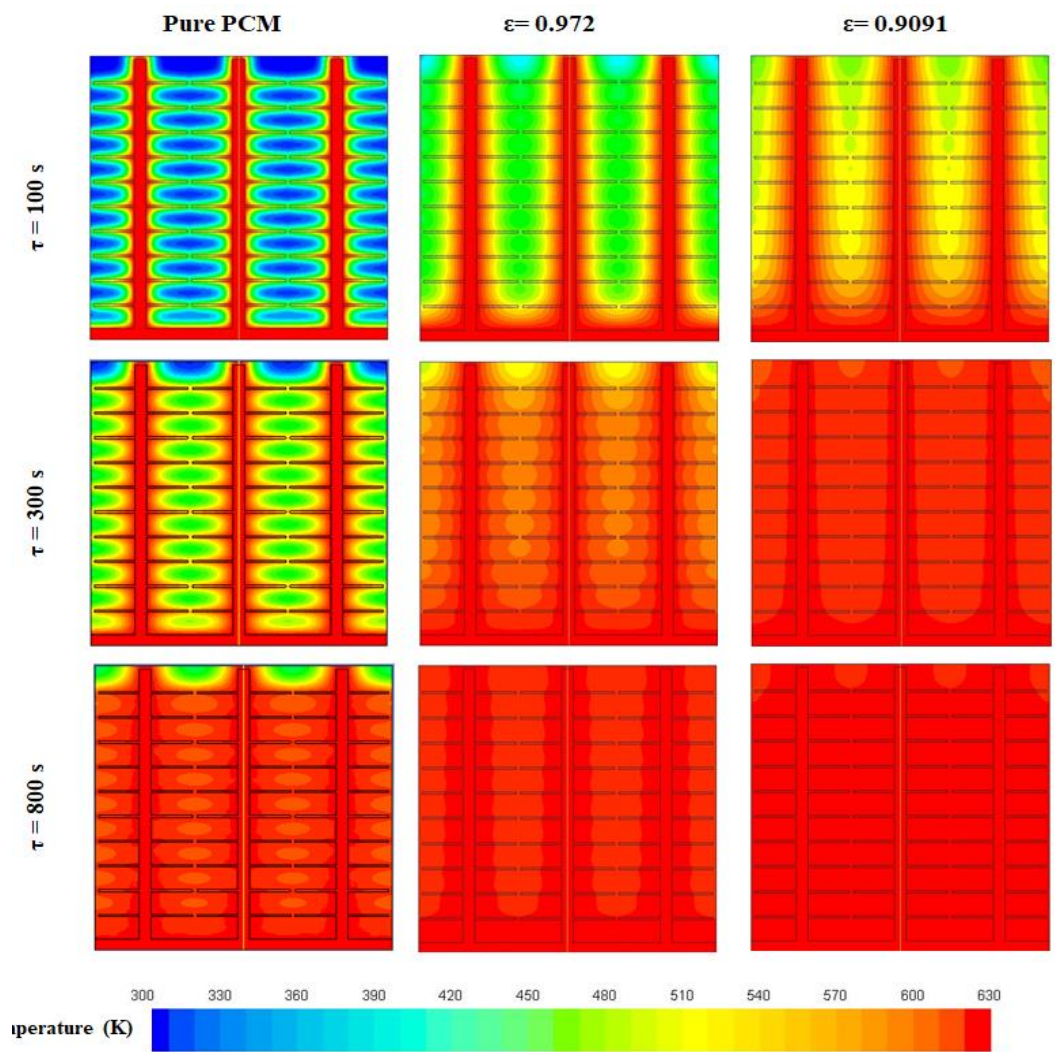

Fig. 3: Effect of metal foam porosity on temperature distribution for the case assisted with three heat pipes.

\section{REFERENCES}

[1] Bondareva, N.S., Sheremet, M.A., "Conjugate heat transfer in the PCM-based heat storage system with finned copper profile: Application in electronics cooling," Int. J. Heat Mass Transf., 124, pp. 1275-1284, (2018).

[2] Fadl, M., Eames, P.C., Guo, "An experimental investigation of the heat transfer and energy storage characteristics of a compact latent heat thermal energy storage system for domestic hot water applications," Energy, 188, (2019).

[3] Raul, A., Saha, S.K., Jain, M., "Transient performance analysis of concentrating solar thermal power plant with finned latent heat thermal energy storage," Renewable Energy, 145, pp. 1957-1971, (2020).

[4] Tiari, S., Mahdavi, M., Thakore, V., Joseph, S., "Thermal Analysis of a High-Temperature Heat Pipe-Assisted Thermal Energy Storage System with Nano-Enhanced Phase Change Material,” Proc. Of ASME Int. Mech. Eng. Congress Expo. IMECE201886481, (2018).

[5] Mahdavi, M., Tiari, S., Pawar, V., "A numerical study on the combined effect of dispersed nanoparticles and embedded heat pipes on melting and solidification of a shell and tube latent heat thermal energy storage system," Journal of Energy Storage, 27, (2020).

[6] Tiari, S., Qiu, S., Mahdavi, M., "Numerical study of finned heat pipe-assisted thermal energy storage system with high temperature phase change material," Energy Convers. Manag., 89, pp. 833-842, (2015).

[7] Buonomo, B., Celik, H., Ercole, D., Oronzio, M., Mobedi, M., "Numerical study on latent thermal energy storage systems with aluminum foam in local thermal equilibrium" Appl. Therm. Eng., 159, (2019).

[8] Shahsavar, A., Al-Rashed, A.A.A.A, Entezari, S., Talebizadeh Sardari, P., "Melting and solidification characteristics of a double-pipe latent heat storage system with sinusoidal wavy channels embedded in a porous medium," Energy, 171, (2019).

[9] Zhu, F., Zhang, C., Gong, X., "Numerical analysis and comparison of the thermal performance enhancement methods for metal foam/phase change material composite," Appl. Therm. Eng, 109, pp. 373-383, (2016).

[10] Mahdavi, M., Tiari, S., Sawyer, C., "Numerical analysis of charging process of a shell and tube latent heat thermal energy storage system with PCM embedded in highly conductive porous material," Proc. Of ASME Int. Mech. Eng. Congress Expo. IMECE2019-11414, (2019). 